\title{
New Air- and Water-Resistive Barriers - Technology Verification
}

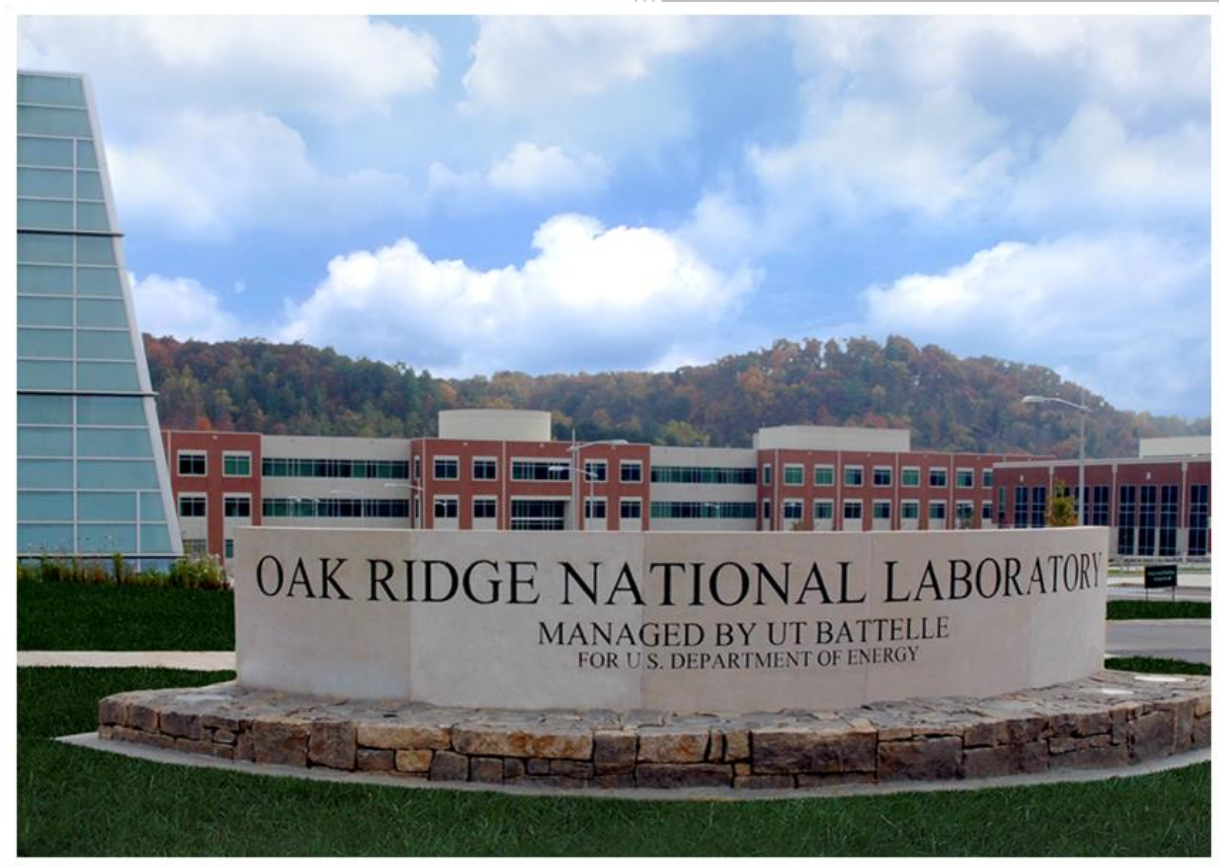

\section{Approved for public release.} Distribution is unlimited.

Diana E. Hun

Mahabir Bhandari

Som S. Shrestha

December 2017 


\title{
DOCUMENT AVAILABILITY
}

Reports produced after January 1, 1996, are generally available free via US Department of Energy (DOE) SciTech Connect.

Website http://www.osti.gov/scitech/

Reports produced before January 1, 1996, may be purchased by members of the public from the following source:

\author{
National Technical Information Service \\ 5285 Port Royal Road \\ Springfield, VA 22161 \\ Telephone 703-605-6000 (1-800-553-6847) \\ TDD 703-487-4639 \\ Fax 703-605-6900 \\ E-mail info@ntis.gov \\ Website http://www.ntis.gov/help/ordermethods.aspx
}

Reports are available to DOE employees, DOE contractors, Energy Technology Data Exchange representatives, and International Nuclear Information System representatives from the following source:

Office of Scientific and Technical Information

PO Box 62

Oak Ridge, TN 37831

Telephone 865-576-8401

Fax 865-576-5728

E-mail reports@osti.gov

Website http://www.osti.gov/contact.html

This report was prepared as an account of work sponsored by an agency of the United States Government. Neither the United States Government nor any agency thereof, nor any of their employees, makes any warranty, express or implied, or assumes any legal liability or responsibility for the accuracy, completeness, or usefulness of any information, apparatus, product, or process disclosed, or represents that its use would not infringe privately owned rights. Reference herein to any specific commercial product, process, or service by trade name, trademark, manufacturer, or otherwise, does not necessarily constitute or imply its endorsement, recommendation, or favoring by the United States Government or any agency thereof. The views and opinions of authors expressed herein do not necessarily state or reflect those of the United States Government or any agency thereof. 
Building Technologies Research and Integration Center

\title{
New Air- and Water-Resistive Barriers Technology Verification
}

\author{
Diana E. Hun \\ Mahabir Bhandari \\ Som S. Shrestha
}

December 2017

Prepared by

OAK RIDGE NATIONAL LABORATORY

Oak Ridge, TN 37831-6283

managed by

UT-BATTELLE, LLC

for the

US DEPARTMENT OF ENERGY

under contract DE-AC05-00OR22725 



\section{TABLE OF CONTENTS}

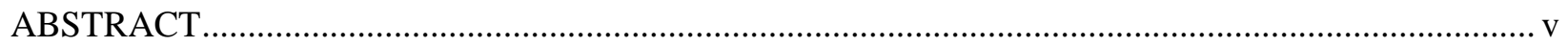

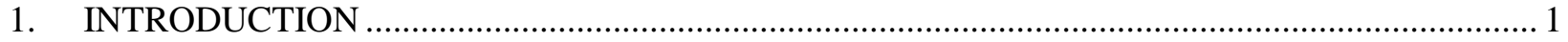

2. NEW AIR-AND WATER- RESISTIVE BARRIERS .......................................................

3. FIELD EVALUATIONS IN COTTAGE GROVE, MN ..................................................... 3

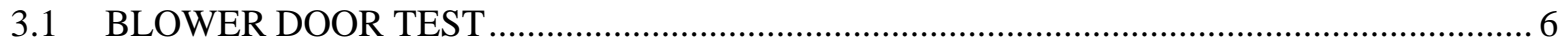

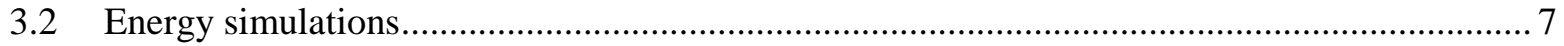

4. FIELD EVALUATIONS IN actual buildings .......................................................... 11

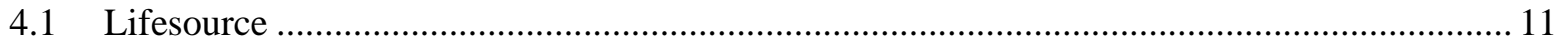

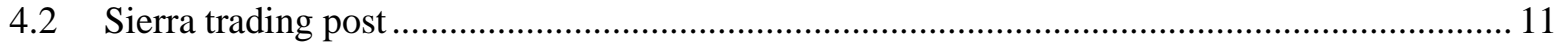

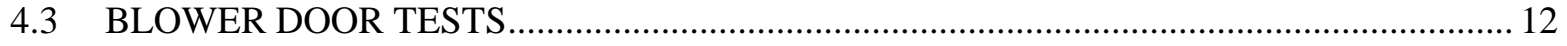

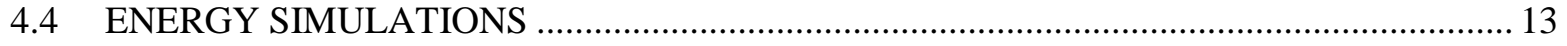

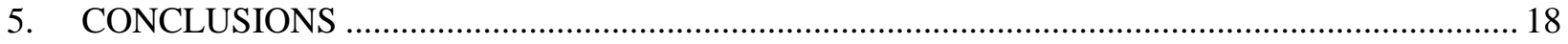

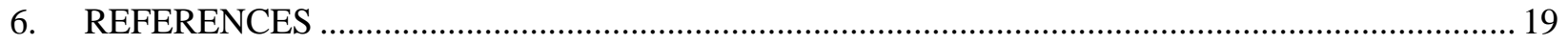




\section{ACKNOWLEDGMENTS}

This report and the work described were sponsored by the Commercial Buildings Integration and the Building Energy Research and Development programs within the Building Technologies Office of the US Department of Energy Office of Energy Efficiency and Renewable Energy. The authors wish to acknowledge the contributions of Amy Jiron and Sven Mumme in guiding this work and the insightful review comments of Andre Desjarlais of Oak Ridge National Laboratory. This work would not have been possible without the contribution from 3M staff members David Gagnon, Tyrone Levesque, Matt Melbye, Craig Moss, Shawn Prestegaard, Francis Tate, and Hermann Golter. We also want to thank those that contributed to the test facilities in Cottage Grove: Kraus-Anderson, the general contractor; BWBR, the architectural firm; and Oldcastle, which supplied the windows. We want to extent our appreciation to Amanda Higgins and Peter Farstad with LifeSource, and to Richard Owens and Tony DiSandro with Sierra Trading Post for giving us access to their buildings. 


\begin{abstract}
Infiltration and exfiltration are among the largest envelope-related contributors to the heating, ventilation, and air conditioning (HVAC) loads in commercial buildings. Air leakage is responsible for about $6 \%$ of the total energy used by the commercial building sector. New air sealing technologies have recently emerged that aim to improve the performance of air barrier systems by simplifying their installation procedure. These include the 3M 3015 primer-less self-adhered membrane, 3M 3015VP vapor permeable primer-less self-adhered membrane, and 3M 2085VP vapor permeable fluid-applied air barrier membrane.
\end{abstract}

ORNL verified the performance of the 3M 3015, 3015VP and 2085VP air- and water- resistive barriers by conducting two field studies. The first one involved side-by-side evaluations in eight unoccupied test facilities in Cottage Grove, $\mathrm{MN}$, that included the $3 \mathrm{M}$ membranes and commonly used air barrier materials such as a self-adhered membrane with primer and a mechanically-fastened membrane with taped joints. The facilities were monitored for 24 months and the collected data were used to calibrate simulation models that in turn were employed to calculate energy consumption and savings because of improvements in airtightness. After two years, results indicate that the test facilities with the new 3M technologies had leakage rates that were slightly lower than the buildings with traditional air barrier materials. The calibrated model for the test facility with the 3M 3015 membrane was used to calculate energy savings due to improved airtightness when compared to a building without an air barrier.

Findings suggest that a building in Minneapolis, MN, or Fairbanks, AK, that has a properly installed air barrier system can have annual HVAC electricity use that is about $36 \%$ lower than if the building did not have an air barrier. Similarly, decreases in natural gas use can be about $25 \%$

The second field evaluation involved the LifeSource building in Minneapolis, MN, and the Sierra Trading Post building in Woodbury, MN. Both of these were recently completed and use the 3M 3015 and 3015VP membranes as their air- and water- resistive barriers, respectively. Blower door test results show that LifeSource has an average air leakage rate of $0.06 \mathrm{cfm} / \mathrm{ft}^{2}$ at $75 \mathrm{~Pa}$, or $85 \%$ lower than the $0.4 \mathrm{cfm} / \mathrm{ft}^{2}$ at $75 \mathrm{~Pa}$ specified in the 2015 International Energy Conservation Code (IECC). The leakage rate in the Sierra building is $0.15 \mathrm{cfm} / \mathrm{ft}^{2}$ at $75 \mathrm{~Pa}$ or $63 \%$ than the IECC value. According to simulation results, LifeSource lowered its annual heating and cooling cost by about $\$ 4,600$ or $10 \%$ when compared to a similar building that lacked an air barrier system. In the case of the Sierra building, savings were $\$ 5,900$ or $41 \%$.

These field evaluations serve as examples of the level of building envelope airtightness that can be achieved by using air barrier materials that are properly installed, and illustrate the energy and financial savings that building envelopes with low air leakage rates could attain. 


\section{INTRODUCTION}

Air leakage, that is, infiltration and exfiltration, through the building envelope is responsible for about 1.1 quads of energy or 6\% of the total energy used by commercial buildings in the US (DOE 2014). Although air sealing technologies are available for purchase, typical installation procedures tend to be complex, time consuming, and rely heavily on quality workmanship. This is especially significant when installing technologies that require multiple components and steps.

New air sealing technologies aim to simplify installation. These include the 3M 3015 primer-less selfadhered membrane, 3M 3015VP vapor permeable primer-less self-adhered membrane, and 3M 2085VP vapor permeable fluid-applied air barrier membrane. Oak Ridge National Laboratory (ORNL) conducted laboratory tests to assess the performance of the 3M 3015 membrane (Hun 2016) under the US-China Clean Energy Research Center for Building Energy Efficiency (https://cercbee.lbl.gov/). These were followed by field evaluations that were intended to provide more realistic insight on the performance of the three 3M membranes. One evaluation involved side-by-side comparisons of the newly developed air barriers and products that are available in the market using test facilities in Cottage Grove, MN. The second assessment involved two recently completed commercial buildings that used the $3 \mathrm{M} 3015$ and 3015VP membranes. The present report describes and summarizes the results from these field studies.

\section{NEW AIR-AND WATER- RESISTIVE BARRIERS}

The effectiveness of an air barrier system highly relies on its ease of installation. In general, the larger the number of components and installation steps, the more likely it is for a mistake to occur that affects performance of the air barrier system. Self-adhered membranes and fluid-applied membranes have emerged as air barrier materials that are potentially more robust than the commonly used mechanicallyfastened membranes. Self-adhered membranes are films that have an adhesive on their back, and are applied on a substrate after the surface has been primed (Figure 1A). Fluid-applied membranes are installed on a substrate either with a roller or a sprayer (Figure 1B) and most of the available products require two passes. Mechanically-fastened membranes are films that are attached to substrates using fasteners with caps and are taped at their joints or edges (Figure 1C). The non-continuous attachment of the mechanically-fastened membrane to the substrate makes it vulnerable to wind as it can tear or detach from the substrate before the cladding is in place (Figure 2).
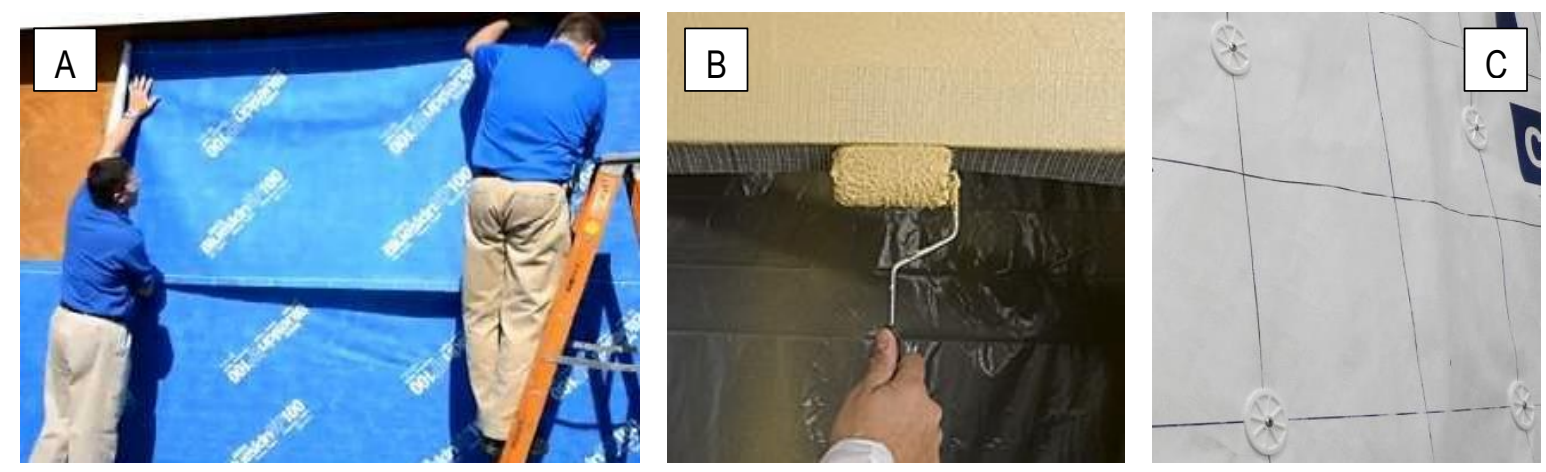

Figure 1. Common air barrier types for commercial buildings. (A) Self-adhered membrane with primer. (B) Fluid-applied membrane. (C) Mechanically-fastened membrane. 

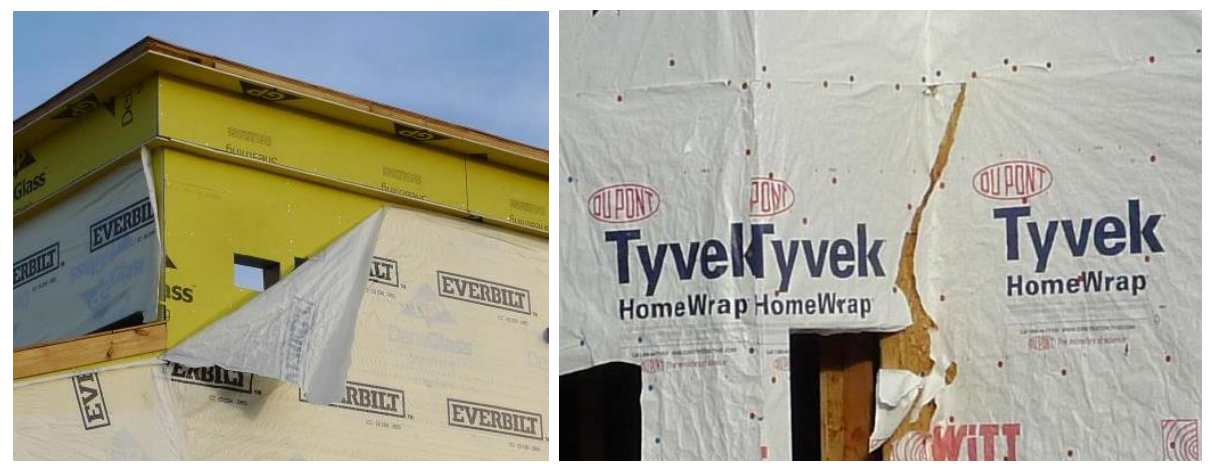

Figure 2. Mechanically-fastened membrane that detached from the substrate likely because of wind.

New versions of self-adhered and fluid-applied membranes have recently been introduced to the market that aim to reduce installation steps, time and errors. These include:

1. 3M 3015 Primer-less self-adhered membrane (Figure 2A): has 0.14 perms and can be installed on most construction materials without having to prime the substrates. ${ }^{1,2}$

2. 3M 3015VP Vapor permeable primer-less self-adhered membrane (Figure 2B): has $\sim 20$ perms and can be installed on most construction materials without having to prime the substrates.

3. 3M 2085VP Vapor permeable fluid-applied air barrier membrane (Figure 2C): has $\sim 30$ perms and can be installed on most construction materials with a single pass.
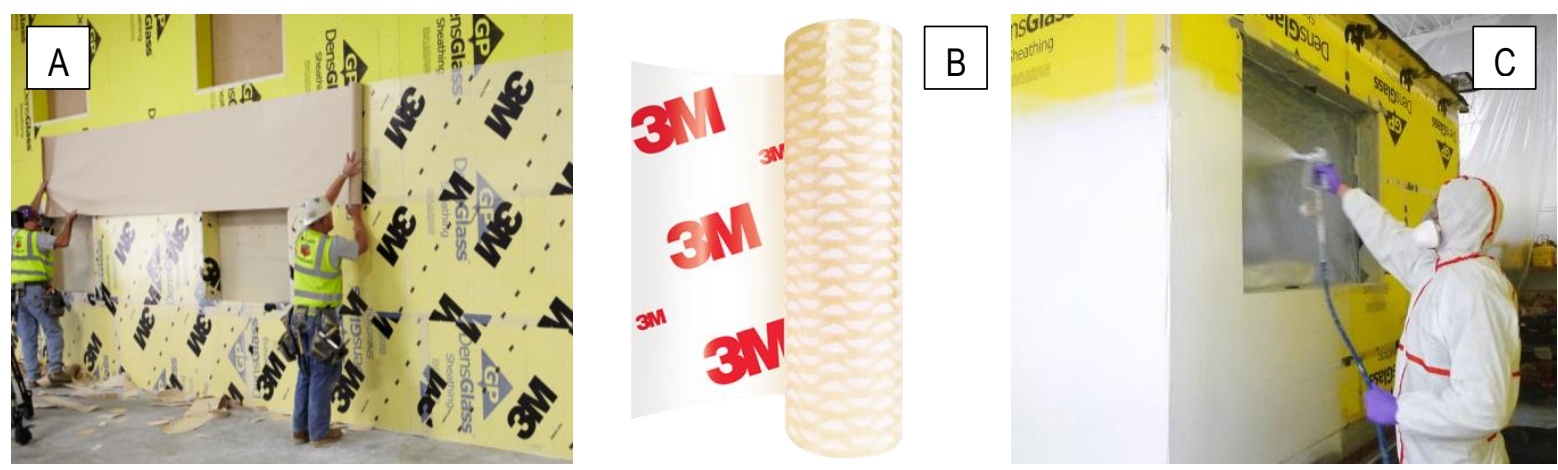

Figure 3. New versions of self-adhered and fluid-applied membranes. (A) 3M 3015 Primer-less selfadhered membrane. (B) 3M 3015VP Vapor permeable primer-less self-adhered membrane. (C) 3M 2085VP Vapor permeable fluid-applied air barrier membrane.

Under the US-China Clean Energy Research Center for Building Energy Efficiency, ORNL assessed the performance of 3M 3015 through laboratory evaluations that followed test standards from the American Society for Testing and Materials (ASTM) International ${ }^{3,4,5,6,7}$ and the American Architectural

\footnotetext{
${ }^{1}$ https://www.youtube.com/watch?v=ChyiuPvMa20

2 https://www.youtube.com/watch?v=2Q9brh0lYjc

${ }_{3}^{3}$ ASTM E283-04. Standard Test Method for Determining Rate of Air Leakage Through Exterior Windows, Curtain Walls, and Doors Under Specified Pressure Differences Across the Specimen.

${ }^{4}$ ASTM E2357-11. Standard Test Method for Determining Air Leakage of Air Barrier Assemblies.

${ }^{5}$ ASTM E1424-91. Standard Test Method for Determining the Rate of Air Leakage Through Exterior Windows, Curtain Walls, and Doors Under Specified Pressure and Temperature Differences Across the Specimen.
} 
Manufacturers Association (AAMA). ${ }^{8}$ The 3015 membrane was installed over fiberglass mat gypsum sheathing in these evaluations. Results indicate that the wall assembly with the 3M 3015 membrane had an air leakage rate that was less than $0.04 \mathrm{cfm} / \mathrm{ft}^{2}$ at $75 \mathrm{~Pa}$ and thus complied with the 2015 International Energy Conservation Code (IECC) requirement. Moreover, water penetration was not observed throughout the tests (Hun 2016).

\section{FIELD EVALUATIONS IN COTTAGE GROVE, MN}

ORNL partnered with $3 \mathrm{M}$ to evaluate the performance of the new air- and water-resistive barriers. To this end, eight test facilities or huts were built offsite and transported and installed at the $3 \mathrm{M}$ plant in Cottage Grove, MN, as illustrated in Figure 4. The huts are $10 \mathrm{ft}$ wide, $14 \mathrm{ft}$ long, and the floor-to-roof deck height is about $8 \mathrm{ft}$. Table 1 lists the material assembly of the envelope, which comply with the 2015 IECC. As shown in Figure 4, the 3015 and 2085VP membranes were installed in two of the facilities and $3015 \mathrm{VP}$ in one. To compare the performance of the new technologies against that of typical membranes, a mechanically-fastened membrane (MFM) and a self-adhered membrane with primer (SAM) were each installed in one facility. Moreover, the baseline consisted of a mechanically-fastened membrane that was installed as a water barrier; that is, the edges of the membrane were not taped but were ship lapped to reduce the potential for water intrusion. This type of installation is still followed by some builders, especially in the residential sector, who don't understand that air leakage leads to higher energy consumption and that the way to prevent this is with a continuous air barrier system in which mechanically-fastened membranes have taped joints. Figures 5 to 6 show the installation of these membranes. The long sides of the buildings had double pane low-e windows. Cooling and heating were provided by mini-splits and baseboard heaters, respectively. Figure 7 shows buildings after construction was completed.

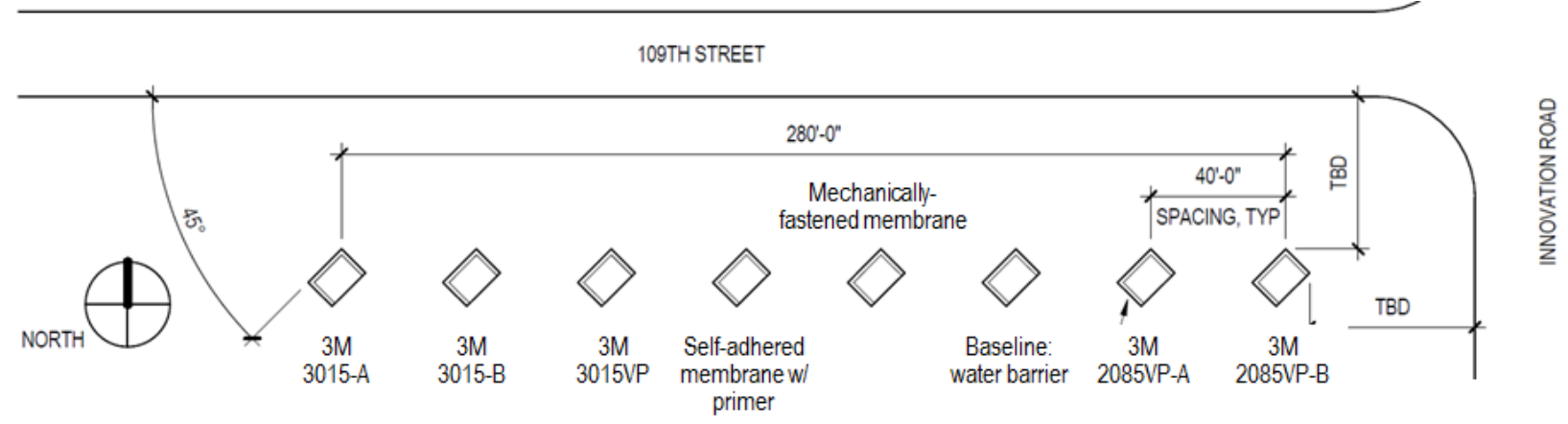

Figure 4. Layout of test facilities at 3M plant in Cottage Grove, MN. The drawing indicates the air and water resistive materials that were installed in each of the huts.

${ }^{6}$ ASTM E331-00. Standard Test Method for Water Penetration of Exterior Windows, Skylights, Doors, and Curtain Walls by Uniform Static Air Pressure Difference.

${ }^{7}$ ASTM E2268-04. Standard Test Method for Water Penetration of Exterior Windows, Skylights, and Doors by Rapid Pulsed Air Pressure Difference.

${ }^{8}$ AAMA 501.5-07. Test Method for Thermal Cycling of Exterior Walls. 
Table 1. Material assembly in the walls, roofs and floor of the test facilities. Materials are listed from outside to inside.

\begin{tabular}{|c|c|c|}
\hline Wall Assembly & Roof Assembly & Floor Assembly \\
\hline $\begin{array}{l}\text { - Metal siding } \\
\text { - } 7 / 8 \text { " metal furring } \\
\text { - } 31 / 2 \text { " mineral wool on "Z" furring } \\
\text { - } 2112 \text { " "Z" furring mounted on } 1 \text { "-thick } \\
\text { XPS spacer at sheathing } \\
\text { - } \text { Air/water barrier as shown in Fig } 4 \\
\text { - } 5 / 8 \text { " gypsum sheathing } \\
\text { - } 6 \text { " steel studs at } 16 \text { " on center } \\
\text { - } 5 / 8 \text { " drywall }\end{array}$ & $\begin{array}{l}\text { - Fully adhered EPDM roofing system } \\
\text { - } 1 / 2 " \text { cover board } \\
\text { - } 6 \text { " to } 41 / 2 " \text { sloping polyisocyanurate } \\
\text { insulation } \\
\text { - Composite sheet vapor retarder } \\
\text { - } 1 / 1 " \text { " gypsum sheathing } \\
\text { - } 11 / 2 " \text { metal decking } \\
\text { - } 6 \text { " steel stud roof joist } \\
\text { - } 5 / 8 \text { " drywall }\end{array}$ & $\begin{array}{l}\text { - } 3 / 4 \text { " exterior grade plywood } \\
\text { - (3) 2" mineral wool w/ } 2 \text { " "Z" furring } \\
\text { - } 6 \text { " steel stud floor joist } \\
\text { - } 11 / 2 \text { " metal decking } \\
\text { - } 3 / 4^{\prime \prime} \text { tongue and groove plywood }\end{array}$ \\
\hline
\end{tabular}
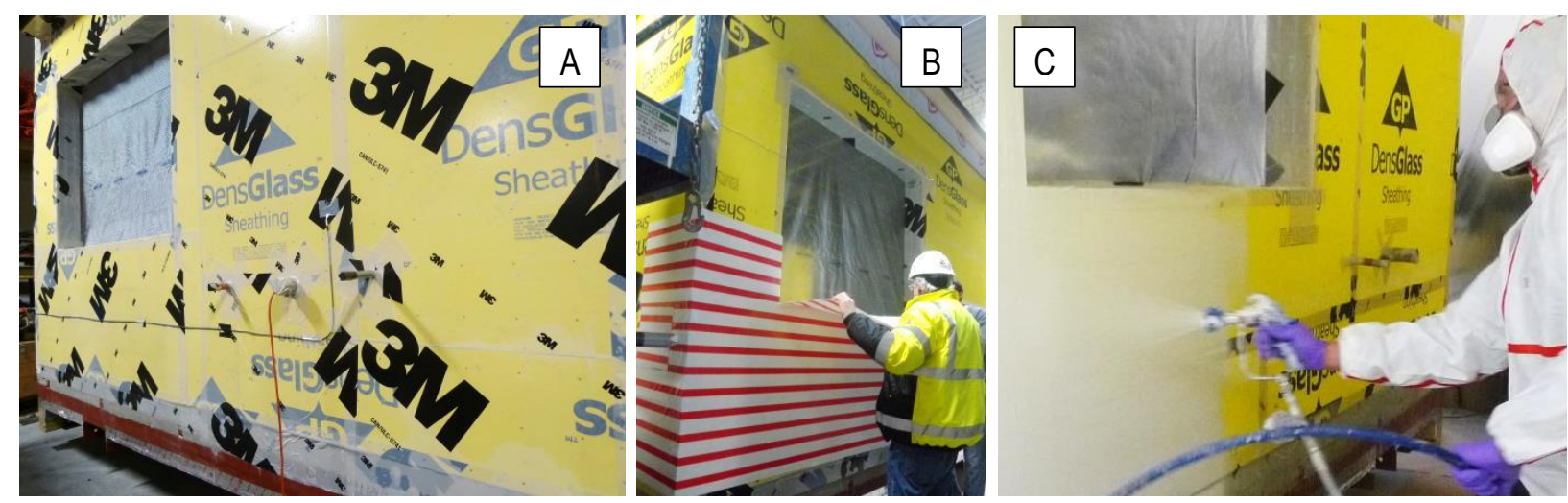

Figure 5. Installation of air- and water- resistive barriers on the test facilities at Cottage Grove, MN. (A) 3M 3015 primer-less self-adhered membrane, (B) 3M 3015VP vapor permeable primer-less self-adhered membrane, and (C) 3M 2085VP vapor permeable fluid-applied membrane.
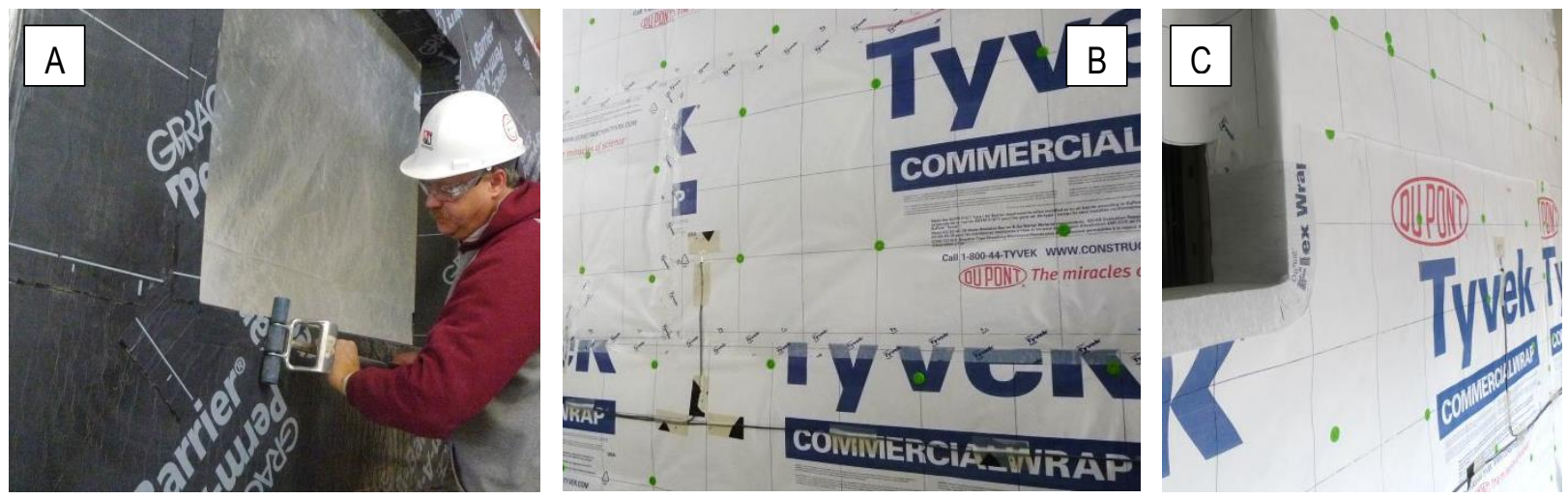

Figure 6. Installation of air- and water- resistive barriers on the test facilities at Cottage Grove, MN. (A) self-adhered membrane with primer, (B) mechanically-fastened membrane, and (C) baseline: mechanically-fastened membrane as a water-resistive barrier (i.e., membrane joints were not taped). 


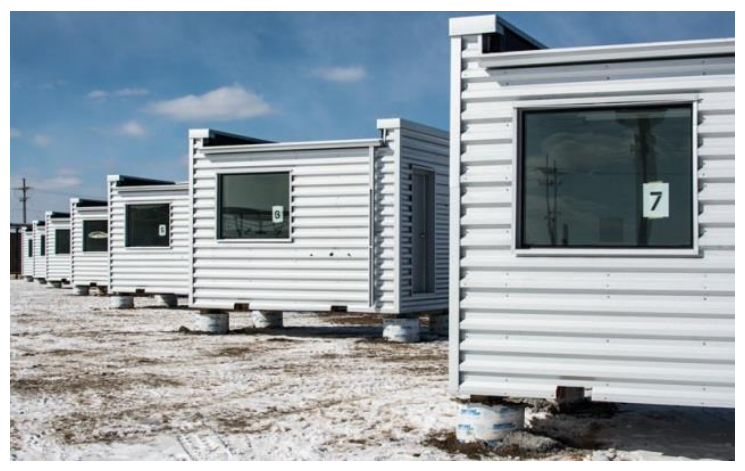

Figure 7. Eight test facilities after construction was completed.

The envelopes of the test facilities were instrumented with temperature, relative humidity and heat flux sensors as described in Figure 8 and Table 2. Energy use was also monitored in each of the huts. Additionally, a weather station was installed onsite to measure outdoor temperature, relative humidity, solar radiation, barometric pressure, and wind speed and direction. Measurements were gathered every 15 minutes and these were saved as hourly averages from October 2015 until September 2017. The buildings were unoccupied during monitoring period.
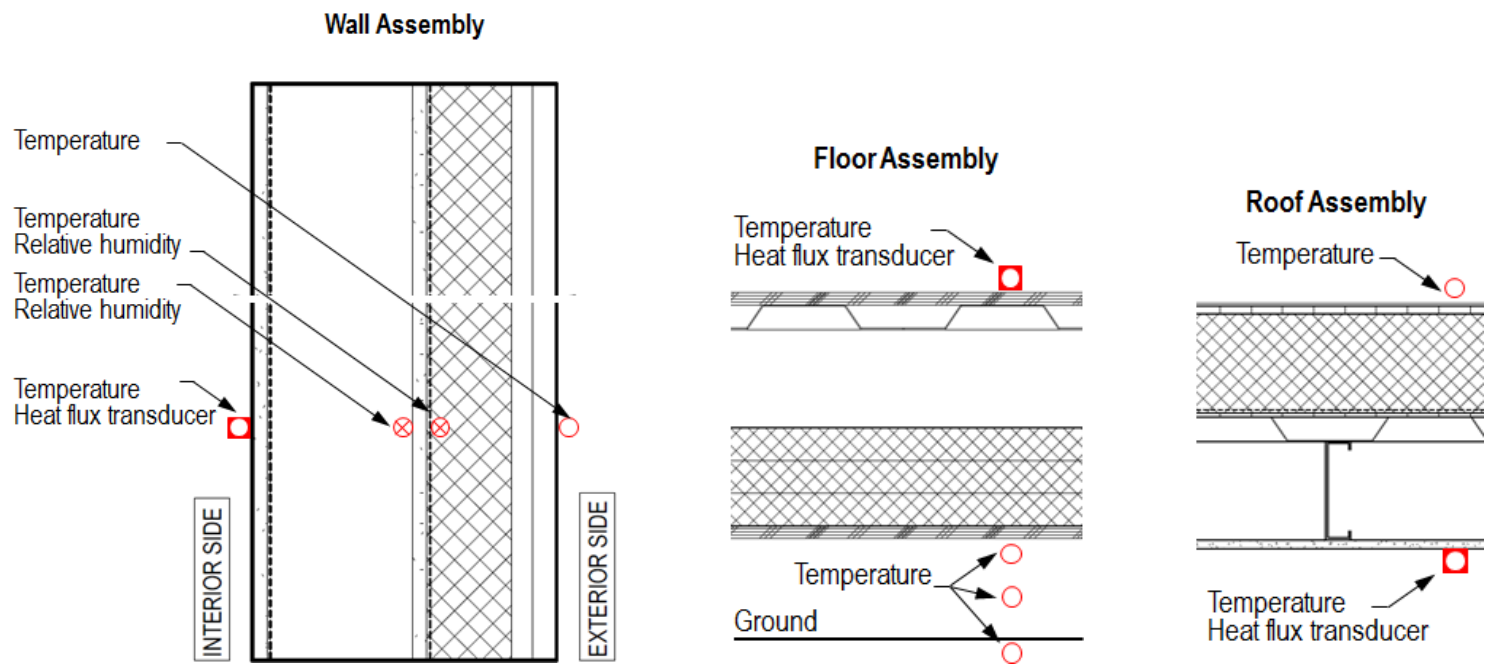

Figure 8. Location of temperature, relative humidity and heat flux sensors in the envelope of the test facilities. Sensors were placed on the four walls of the buildings. 
Table 2. Sensors that were installed in the eight test facilities at Cottage Grove, MN, and at the weather station.

\begin{tabular}{lcc}
\hline \multicolumn{1}{c}{ Parameter } & Manufacturer & Sensor Model \\
\hline Wall panels and indoors & & \\
\hline Temperature & Honeywell/Fenwal & $192-103$ LET-A01 \\
Relative humidity & Honeywell & HIH-4000 \\
Heat flux & Concept Engineering & F-002-4 \\
\hline Weather station & & \\
\hline Temperature & Campbell Scientific & CS215 \\
Relative humidity & Campbell Scientific & CS215 \\
Wind speed/direction & Gill & WindSonic \\
Solar radiation & Campbell Scientific & LI200X \\
Atmospheric pressure & Vaisala & CS106 \\
\hline Total energy and mini-split energy & & \\
\hline Energy & \multirow{2}{*}{ Continental Control Systems } & WattNode WNB-3Y-208-P \\
\hline
\end{tabular}

\subsection{BLOWER DOOR TEST}

ORNL conducted seasonal blower door tests in each of the test facilities according to ASTM E779-10. ${ }^{9}$ Figures 9 and 10 show the exfiltration or pressurization and infiltration or depressurization results, respectively. As expected, exfiltration results are higher than the infiltration values because leakage paths tend to open when buildings are pressurized and close when buildings are depressurized. Nevertheless, all of the test facilities had air leakage rates that were lower than the $0.4 \mathrm{cfm} / \mathrm{ft}^{2}$ at $75 \mathrm{~Pa}$ that is prescribed in the 2015 IECC. This included the baseline hut, which is the facility with a mechanically-fastened membrane that was not taped at joints. The low leakage rate of the baseline hut is likely due to the presence of a continuous exterior insulation that pressed the membrane against the exterior substrate (Figure 8) and kept the membrane in place during the blower door tests. Figures 9 and 10 also indicate that the test facilities with the $3 \mathrm{M}$ membranes had leakage rates that were slightly lower than the buildings with traditional air barrier materials, that is, self-adhered membrane with primer and mechanically-fastened membrane with taped joints. Furthermore, blower door measurements suggest that there was not deterioration in the performance of the air barrier systems after two years, but these results may have been influenced by the fact that the buildings were unoccupied and not subjected to the wear and tear from occupant use.

\footnotetext{
${ }^{9}$ ASTM E779-10. Standard Test Method for Determining Air Leakage Rate by Fan Pressurization.
} 


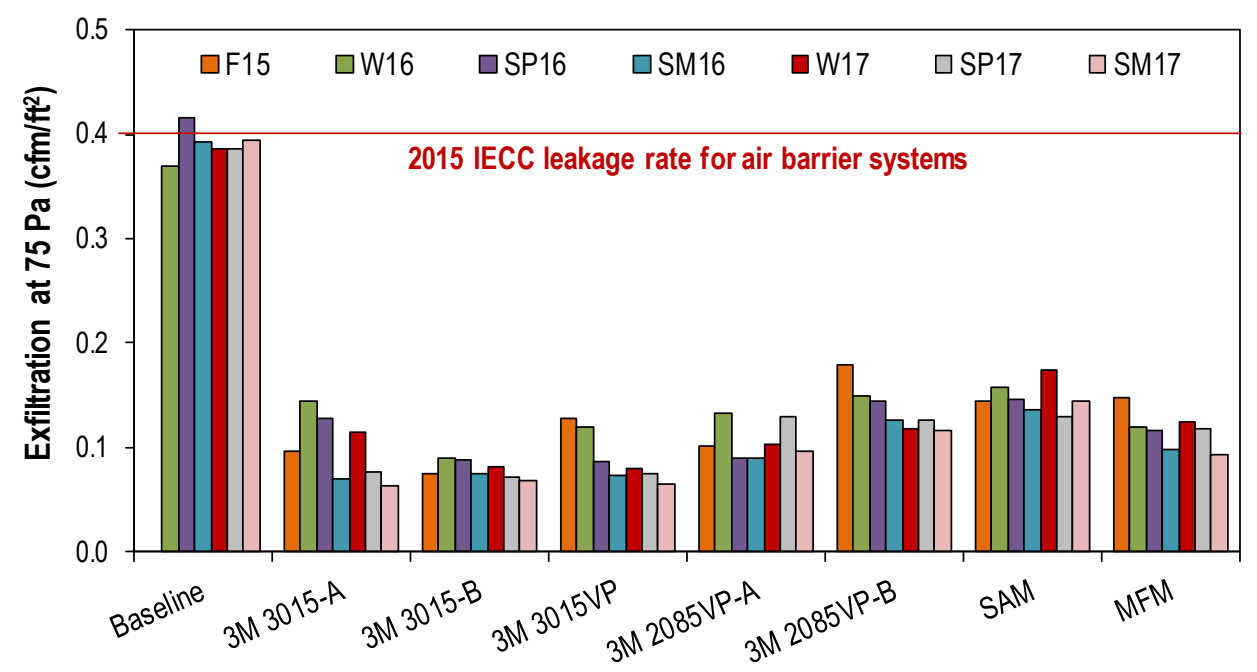

Figure 9. Air leakage rates of test facilities in Cottage Grove, MN, under positive pressure. Results indicate that all buildings with an air barrier meet the International Energy Conservation Code's requirement almost two years after installation. Abbreviations: F, fall; MFM, mechanically-fastened membrane; SAM, self-adhered membrane with primer; SM, summer; SP, spring; W, winter.

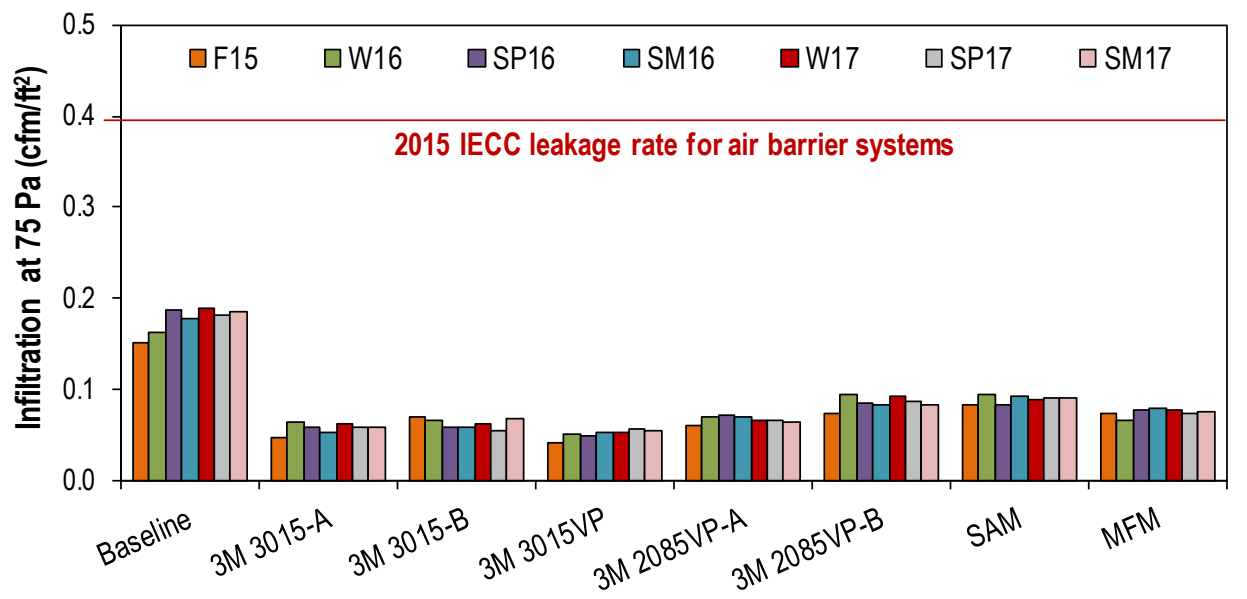

Figure 10. Air leakage rates of test facilities in Cottage Grove, MN, under negative pressure. Results indicate that all buildings with an air barrier meet the International Energy Conservation Code's requirement almost two years after installation. Abbreviations: F, fall; MFM, mechanically-fastened membrane; SAM, self-adhered membrane with primer; SM, summer; SP, spring; W, winter.

\subsection{ENERGY SIMULATIONS}

Although energy consumption was monitored in each of the test huts, these data could not be used for comparison purposes because the indoor temperatures in the facilities were not identical. Instead, simulation models were generated and calibrated for each of the huts, and used to evaluate the effect of the different air barrier materials on energy use.

The DOE's whole building energy simulation software EnergyPlus ${ }^{\mathrm{TM}}$ ver 8.3 (DOE 2016a) was used to generate simulation models for the test huts. The average value from the pressurization and depressurization blower door tests was utilized in the models to calculate the air leakage through the 
building envelope. The models were calibrated with the following measured data that were collected from May 2016 to April 2017: outdoor and indoor temperature, outdoor relative humidity, wind speed,

barometric pressure, direct beam solar radiation, and diffuse solar radiation. The performance of the minisplit air-conditioning system was modeled using the manufacturer's specifications. The calibrated models were used in conjunction with the measured weather data and indoor air temperature from each of the facilities to calculate their energy use. The calculated and measured monthly energy consumption values were compared by determining the normalized mean bias error (NMBE) and the coefficient of variance root mean square error (CV-RMSE). According to ASHRAE Guideline 14 (ASHRAE 2014), the accepted tolerances for these statistical parameters are $\pm 5 \%$ and $\pm 15 \%$, respectively. Table 3 indicates that the results from the eight facilities met the ASHRAE Guideline 14 compliance criteria. Figure 11 is an example of how the measured energy consumption compared to the results from the calibrated models.

Table 3. Normalized mean bias error (NMBE) and coefficient of variance root mean square error (CVRMSE) that were obtained from the comparison of calculated and measured monthly energy consumption values.

\begin{tabular}{lcc}
\hline $\begin{array}{l}\text { Type of air- and water- resistive } \\
\text { barrier in test facility }\end{array}$ & Normalized mean bias error (\%) & $\begin{array}{c}\text { Coefficient of variance root mean } \\
\text { square error (\%) }\end{array}$ \\
\hline Baseline & -2.10 & 6.33 \\
\hline 3M 3015-A & 1.86 & 4.72 \\
\hline 3M 3015-B & 0.50 & 4.48 \\
\hline 3M 3015VP & 1.29 & 4.77 \\
\hline 3M 2085VP-A & 2.21 & 5.90 \\
\hline 3M 2085VP-B & 3.49 & 5.92 \\
\hline Self-adhered membrane w/ primer & 0.14 & 5.02 \\
\hline Mechanically-fastened membrane & 1.95 & 4.83 \\
\hline
\end{tabular}

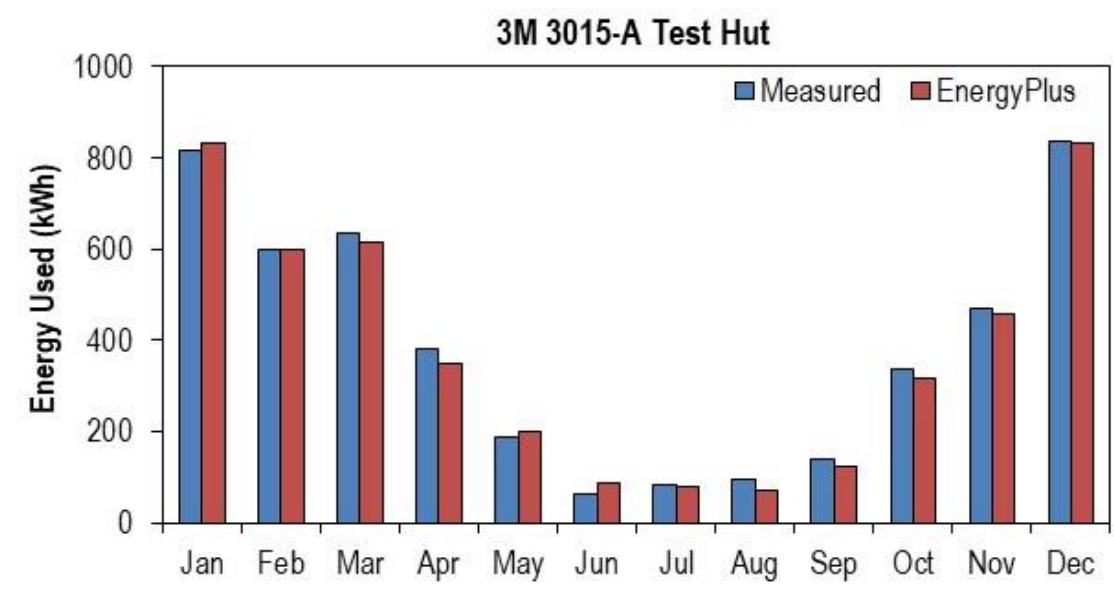

Figure 11. Measured and calculated energy used in the 3M 3015-A test facility. The calculated values were obtained from an EnergyPlus model that complied with ASHRAE Guideline 14 after it was calibrated using collected measurements.

The calibrated models were used to estimate the annual energy consumed to cool and heat each of the test huts. The weather profile was obtained from the Typical Meteorological Year (TMY) data for Minneapolis/St Paul, MN. The heating, ventilation, and air conditioning (HVAC) system, thermostat set 
point, occupancy, lighting, plug load, mechanical ventilation, and internal mass were based on the DOE commercial prototype building model for small offices (DOE 2016b). The HVAC system consisted of a unitary heat pump that was supplemented by a gas furnace; thus, electricity was used for both cooling and heating. Figures 12 and 13 show that all the huts needed comparable amounts of electricity and natural gas. These results indicate that the new $3 \mathrm{M}$ air barrier materials performed in a similar manner as the readily available technologies. The baseline hut did not utilize much larger amounts of energy than the other buildings because, as it was previously discussed, the air leakage rate of its envelope was relatively low.

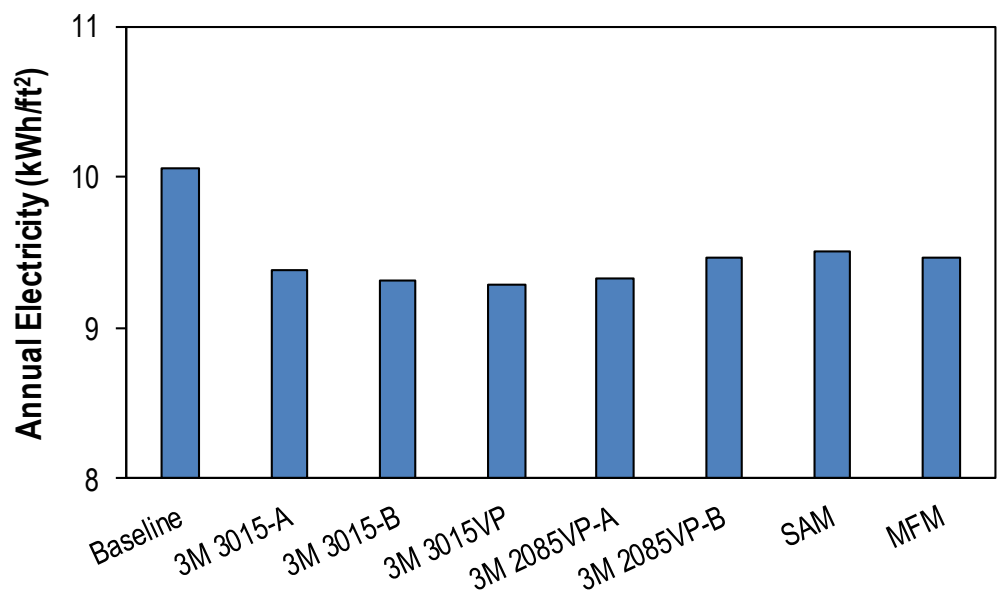

Figure 12. Annual electricity used to cool and heat the test buildings with different air barrier materials. These results were calculated using the calibrated EnergyPlus simulation models. Abbreviations: MFM, mechanically-fastened membrane; SAM, self-adhered membrane with primer.

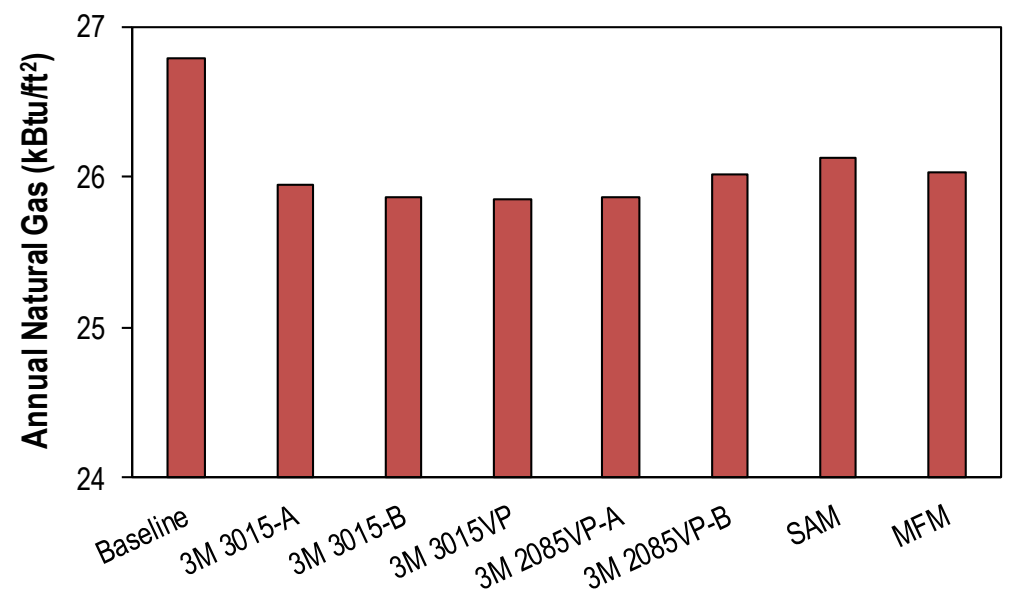

Figure 13. Annual natural gas used to heat the test buildings with different air barrier materials. These results were calculated using the calibrated EnergyPlus simulation models. Abbreviations: MFM, mechanically-fastened membrane; SAM, self-adhered membrane with primer.

The calibrated model for the 3M 3015-A test hut was used to calculate the energy savings due to improved airtightness. To this end, simulations were performed using the measured air leakage rate of this test building $\left(0.07 \mathrm{cfm} / \mathrm{ft}^{2}\right.$ at $\left.75 \mathrm{~Pa}\right)$ and the average air leakage rate reported by Persily and Emmerich (2014) for commercial buildings without an air barrier $\left(1.3 \mathrm{cfm} / \mathrm{ft}^{2}\right.$ at $\left.75 \mathrm{~Pa}\right)$. These leakage rates are for 5-sided buildings, that is, only the walls and roofs are considered as leakage areas as it is assumed that air leaks are not present in the foundation. Simulations were conducted in cities with different outdoor 
conditions: Miami, FL, Phoenix, AZ, Baltimore, MA, Minneapolis, MN, and Fairbanks, AK. As in the previous simulations, assumptions were based on the DOE commercial prototype building model for small offices (DOE 2016b), and the HVAC system consisted of a unitary heat pump that was supplemented by a gas furnace. Figures 14 and 15 illustrate how the annual electricity and natural gas consumption are affected by higher air leakage rates. This is especially the case in northern cities such as Minneapolis and Fairbanks, where a properly installed air barrier system can decrease annual electricity and natural gas use by about $36 \%$ and $25 \%$, respectively.

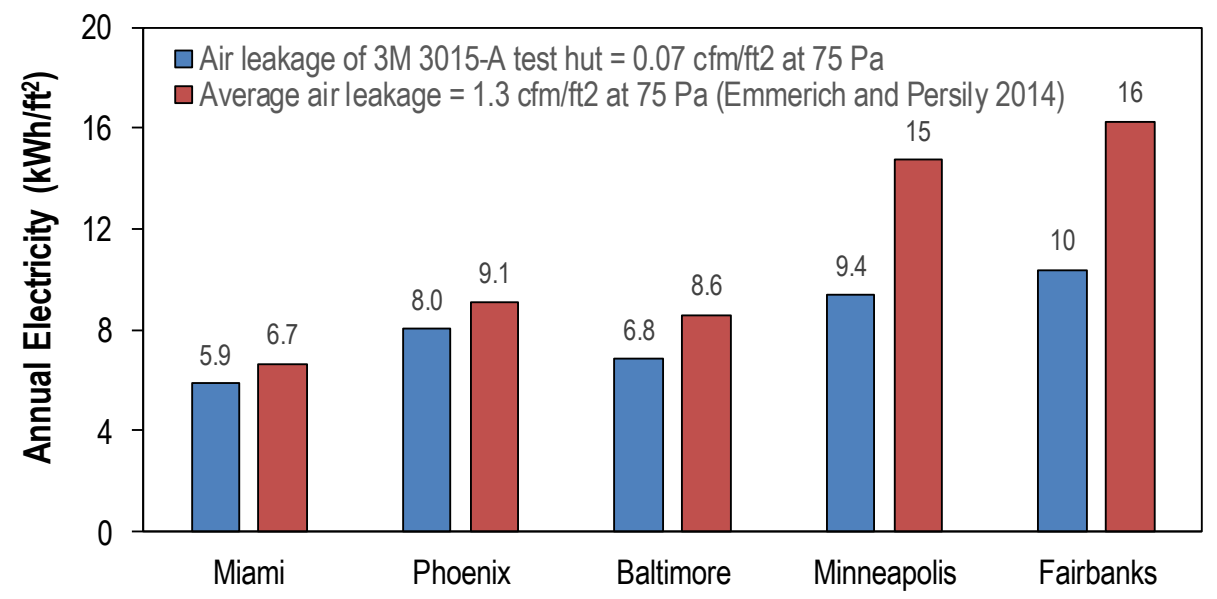

Figure 14. Annual electricity needed to cool and heat the $3 \mathrm{M} 3015-\mathrm{A}$ test hut $\left(0.07 \mathrm{cfm} / \mathrm{ft}^{2}\right.$ at $\left.75 \mathrm{~Pa}\right)$ and a similar structure with the air leakage rate of a building without an air barrier $\left(1.3 \mathrm{cfm} / \mathrm{ft}^{2}\right.$ at $\left.75 \mathrm{~Pa}\right)$ using a unitary heat pump. These results were calculated using calibrated EnergyPlus simulation models.

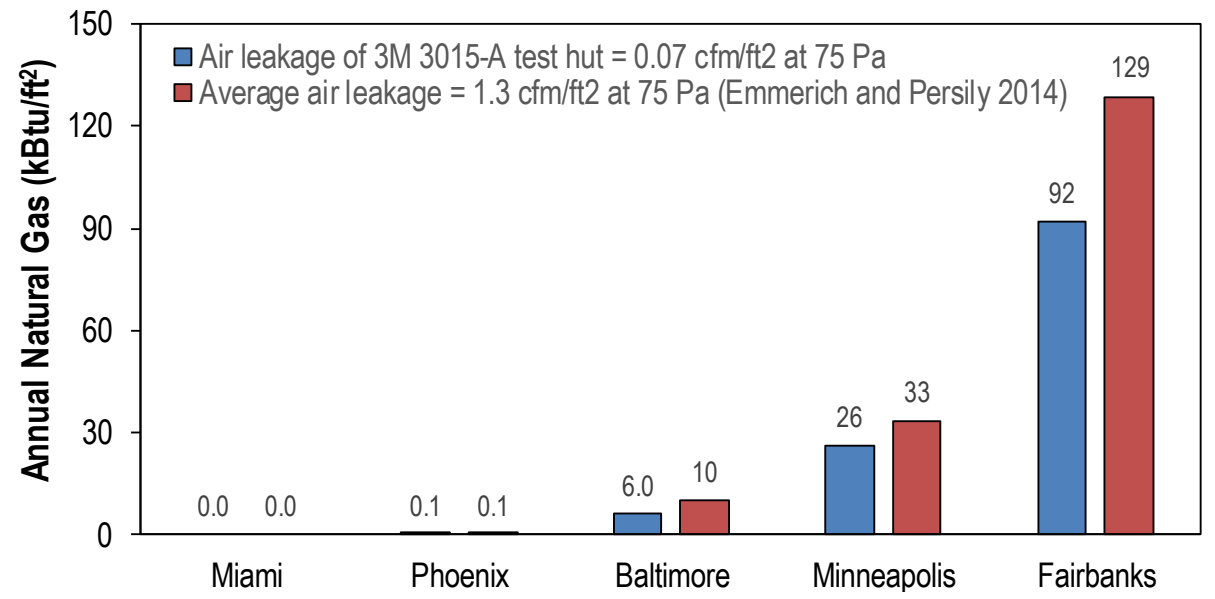

Figure 15. Annual natural gas needed to heat the $3 \mathrm{M} 3015-\mathrm{A}$ test hut $\left(0.07 \mathrm{cfm} / \mathrm{ft}^{2}\right.$ at $\left.75 \mathrm{~Pa}\right)$ and a similar structure with the air leakage rate of a building without an air barrier $\left(1.3 \mathrm{cfm} / \mathrm{ft}^{2}\right.$ at $\left.75 \mathrm{~Pa}\right)$ using a supplementary gas furnace. These results were calculated using calibrated EnergyPlus simulation models. 


\section{FIELD EVALUATIONS IN ACTUAL BUILDINGS}

\subsection{LIFESOURCE}

The LifeSource building in Minneapolis, MN, served as a site for third party verification of the 3M 3015 primer-less self-adhered membrane. LifeSource is an organ donation center that works with hospitals and community partners to support donor families, manage the donation process, and educate the community. The building shown in Figures 16 and 17 was completed in 2015 and complies with the 2007 Minnesota State Building Code and the 2006 International Building Code. The structure has two stories with 32,000 $\mathrm{ft}^{2}$ on the first floor and $18,000 \mathrm{ft}^{2}$ on the second floor, which are primarily used as offices and laboratories. The 3M 3015 membrane was used as the main air- and water-resistive barrier material on the exterior opaque walls.
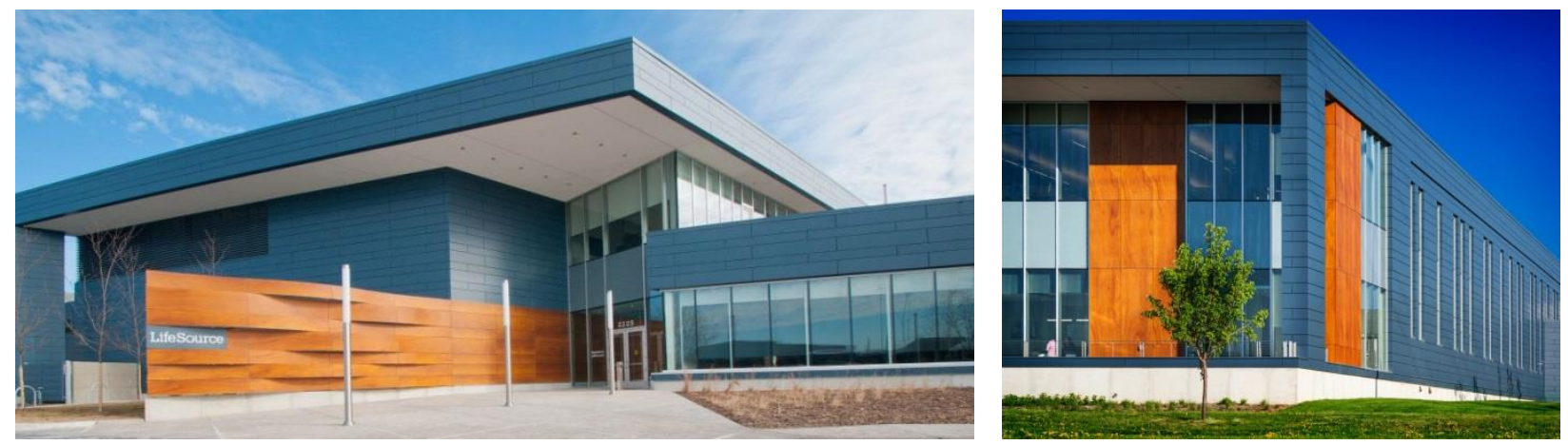

Figure 16. The LifeSource building in Minneapolis, MN, uses the 3M 3015 primer-less self-adhered membrane as its main air- and water-resistive barrier material.
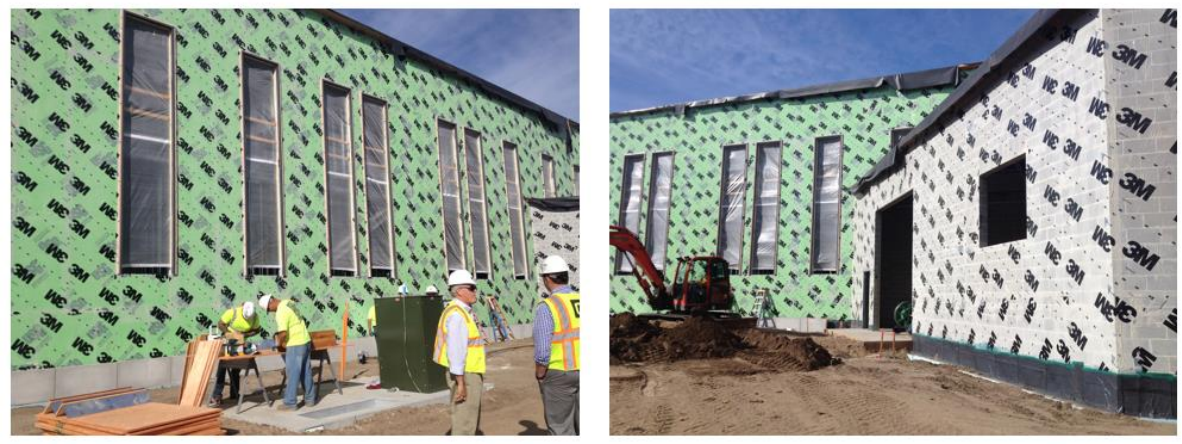

Figure 17. Installation of the 3M 3015 primer-less self-adhered membrane on exterior grade drywall and concrete masonry units.

\subsection{SIERRA TRADING POST}

The Sierra Trading Post building in Woodbury, MN, served as a verification site for the 3M 3015VP vapor permeable primer-less self-adhered membrane. As shown in Figure 18, Sierra is a one-story retail building with a footprint of about $20,000 \mathrm{ft}^{2}$. The building was completed in 2017 and complies with the 2012 Minnesota State Building Code and the 2012 International Building Code. The 3M 3015VP membrane was used as the main air- and water-resistive barrier material on the exterior opaque walls. 

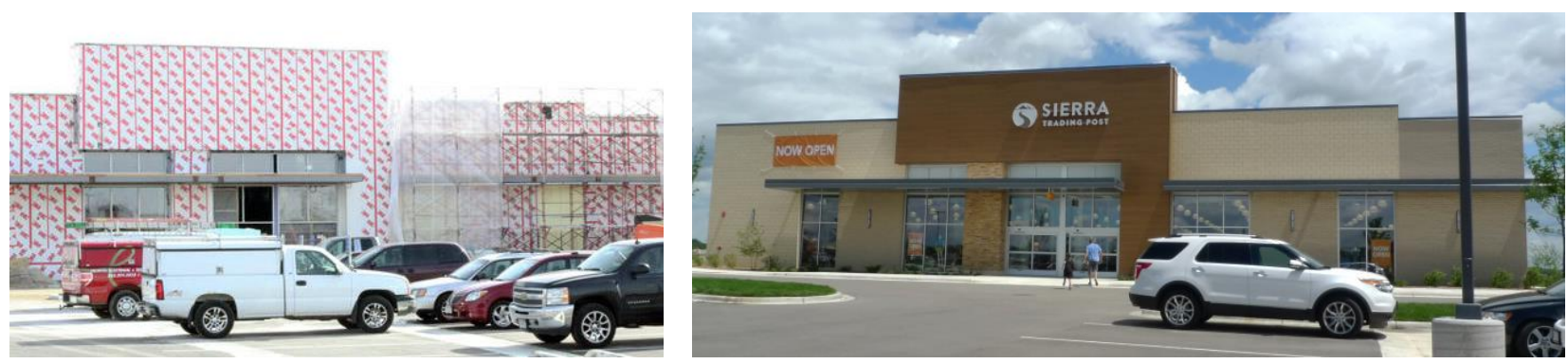

Figure 18. The Sierra Trading Post building in Woodbury, MN, uses the 3M 3015VP vapor permeable primer-less self-adhered membrane as its main air- and water-resistive barrier material.

\subsection{BLOWER DOOR TESTS}

ORNL hired the Center for Energy and Environment (CEE) as the blower door consultant to measure the air leakage rate of the LifeSource and the Sierra Trading Post buildings. CEE conducted the tests according to ASTM E779-10. ${ }^{10}$ To close mechanical penetrations, CEE used mechanical dampers in LifeSource and self-adhered films in Sierra. The measured leakage rates are summarized in Table 4. Leakage rates when LifeSource was depressurized and pressurized to $\pm 75 \mathrm{~Pa}$ were 5,408 and 6,071 cfm, respectively. Pressurization values are typically higher because dampers and doors tend to slightly open when the building is under positive pressure. Results indicate that LifeSource has an average air leakage of $0.06 \mathrm{cfm} / \mathrm{ft}^{2}$ at $75 \mathrm{~Pa}$, which is $85 \%$ lower than the $0.4 \mathrm{cfm} / \mathrm{ft}^{2}$ at $75 \mathrm{~Pa}$ specified in the 2015 IECC. Blower door measurements indicate that Sierra had leakage rates of 7,973 and 8,085 cfm when pressurized and depressurized to $\pm 75 \mathrm{~Pa}$, respectively. These values indicate that Sierra has an average leakage of $0.15 \mathrm{cfm} / \mathrm{ft}^{2}$ at $75 \mathrm{~Pa}$, which is $63 \%$ lower than what is specified by the 2015 IECC.

Table 5 compares the air leakage measurements from LifeSource and Sierra to that of commercial and institutional buildings from a database compiled by the National Institute of Standards and Technology (Emmerich and Persily 2014). The data indicate that the airtightness level of LifeSource is $\mathbf{7 9 \%}$ lower than the average value of $0.28 \mathrm{cfm} / \mathrm{ft}^{2}$ at $75 \mathrm{~Pa}$ from 79 commercial buildings with air barriers, and $93 \%$ less than the average value of $0.86 \mathrm{cfm} / \mathrm{ft}^{2}$ at $75 \mathrm{~Pa}$ from 290 buildings without air barriers. In the case of Sierra, these decreases in air leakage translate to $46 \%$ and $83 \%$, respectively. These results indicate that both LifeSource and Sierra have relatively tight envelopes.

\footnotetext{
${ }^{10}$ Standard Test Method for Determining Air Leakage Rate by Fan Pressurization.
} 
Table 4. Blower door test results from the LifeSource and Sierra Trading Post buildings.

\begin{tabular}{|c|c|c|c|}
\hline Measurements & Depressurization & Pressurization & Average \\
\hline \multicolumn{4}{|c|}{ LifeSource Building } \\
\hline \multicolumn{4}{|l|}{ Leakage rates at $75 \mathrm{~Pa}$} \\
\hline Airflow (cfm) & $5,408( \pm 1.7 \%)$ & $6,071( \pm 2.3 \%)$ & $5,740( \pm 1.5 \%)$ \\
\hline Air leakage $\left(\mathrm{cfm}^{2} \mathrm{ft}^{2}\right)^{\mathrm{a}}$ & 0.056 & 0.063 & 0.06 \\
\hline \multicolumn{4}{|l|}{ Airflow equation } \\
\hline Flow coefficient $\left(\mathrm{C}, \mathrm{cfm} / \mathrm{Pa}^{\mathrm{n}}\right)$ & $418.9( \pm 13.7 \%)$ & $274.8( \pm 24.2 \%)$ & 347 \\
\hline Exponent ( $\mathrm{n}$, dimensionless) & $0.592( \pm 0.035)$ & $0.717( \pm 0.06)$ & 0.655 \\
\hline Correlation coefficient & 0.9931 & 0.9842 & \\
\hline \multicolumn{4}{|c|}{ Sierra Trading Post Building } \\
\hline \multicolumn{4}{|l|}{ Leakage rates at $75 \mathrm{~Pa}$} \\
\hline Airflow (cfm) & $7,973( \pm 0.7 \%)$ & $8,085( \pm 1.8 \%)$ & $8,029( \pm 1.0 \%)$ \\
\hline Air leakage $\left(\mathrm{cfm} / \mathrm{ft}^{2}\right)^{\mathrm{b}}$ & 0.145 & 0.147 & 0.146 \\
\hline \multicolumn{4}{|l|}{ Airflow equation } \\
\hline Flow coefficient $\left(\mathrm{C}, \mathrm{cfm} / \mathrm{Pa}^{\mathrm{n}}\right)$ & $614.1( \pm 4.2 \%)$ & $740.2( \pm 11.9 \%)$ & 677.2 \\
\hline Exponent ( $\mathrm{n}$, dimensionless) & $0.594( \pm 0.011 \%)$ & $0.554( \pm 0.03 \%)$ & 0.574 \\
\hline Correlation coefficient & 0.9992 & 0.994 & \\
\hline $\begin{array}{l}\text { a. Normalization is based or } \\
\text { into account. Their sum e } \\
\text { b. Normalization is based or } \\
\text { into account. Their sum e }\end{array}$ & $\begin{array}{l}\text {-sided building; that } \\
\text { in the LifeSource bu } \\
\text {-sided building; that } \\
\text { in the Sierra building }\end{array}$ & $\begin{array}{l}\text { exterior walls, } \\
\text { g. } \\
\text { e exterior walls, }\end{array}$ & $\begin{array}{l}\text { d floor are taken } \\
\text { d floor are taken }\end{array}$ \\
\hline
\end{tabular}

Table 5. Comparison of the measured air leakage rates to those in the database compiled by the National Institute of Standards and Technology (NIST).

\begin{tabular}{|c|c|c|c|c|}
\hline \multicolumn{3}{|c|}{ NIST Database } & \multicolumn{2}{|c|}{ Air leakage from present validation studies } \\
\hline Cases & $\begin{array}{l}\text { Sample } \\
\text { size }\end{array}$ & $\begin{array}{l}\text { Average air leakage } \\
\left(\mathrm{cfm} / \mathrm{ft}^{2}\right) \text { at } 75 \mathrm{~Pa}^{\mathrm{a}}\end{array}$ & $\begin{array}{c}\text { LifeSource }= \\
0.06 \mathrm{cfm} / \mathrm{ft}^{2} \text { at } 75 \mathrm{~Pa}\end{array}$ & $\begin{array}{l}\text { Sierra Trading Post }= \\
0.15 \mathrm{cfm} / \mathrm{ft}^{2} \text { at } 75 \mathrm{~Pa}\end{array}$ \\
\hline Buildings w/ air barrier & 79 & 0.28 & $79 \%$ lower & $46 \%$ lower \\
\hline Buildings w/o air barrierb $^{b}$ & 290 & 0.86 & $93 \%$ lower & $83 \%$ lower \\
\hline All buildings & 387 & 0.72 & $92 \%$ lower & $79 \%$ lower \\
\hline
\end{tabular}

a. Emmerich and Persily (2014). Normalization of the leakage rates is based on the area of the exterior walls, roof and floor.

b. These are buildings that were not specified as having an air barrier, but some could have had it in place.

\subsection{ENERGY SIMULATIONS}

Simulation models were created to estimate the energy savings due to the airtightness achieved at the LifeSource and Sierra buildings. EnergyPlus ${ }^{\mathrm{TM}}$ ver 8.3 (DOE 2016a) was used in this task. The building geometry was obtained from the architectural drawings that included the dimensions, floor plans, and construction material layouts. The HVAC system was determined from the mechanical drawings. Internal loads, lighting, HVAC set point temperatures and efficiency, and their respective schedules were primarily based on information from the architectural drawings. When information was missing, 
assumptions were made based on DOE prototype buildings (DOE 2016b) for office and retail buildings. The generated models were not calibrated because building energy consumption data were not available.

The effect of air leakage on energy consumption was evaluated by conducting a parametric analysis. The following airflow equation was used as the basis of this assessment:

$$
Q=C \times \Delta P^{n}
$$

where $Q$ is the air leakage rate in cfm, $C$ is the flow coefficient in $\mathrm{cfm} / \mathrm{Pa}^{\mathrm{n}}, \Delta P$ is the pressure differential in $\mathrm{Pa}$, and $n$ is a dimensionless exponent. Values for $C$ and $n$ are listed in Table 4. Different air leakage rates and energy use were calculated by varying the flow coefficient, given that it is proportional to the size of the holes through which leakage occurs, and by keeping the exponent constant. Additionally, TMY weather data for Minneapolis/St Paul, MN, were used in the simulations.

As previously mentioned, the LifeSource and the Sierra buildings have average air leakage rates of 0.06 $\mathrm{cfm} / \mathrm{ft}^{2}$ and $0.15 \mathrm{cfm} / \mathrm{ft}^{2}$ at $75 \mathrm{~Pa}$, respectively, which are the blower door measurements normalized with respect to the area of the above grade walls, roof, and slab on grade per the IECC. In contrast, simulation models use air leakage rates that are normalized using only the area of the above grade walls and roof because air typically does not leak through the slab on grade. Consequently, the leakage rates used in the simulations were $0.09 \mathrm{cfm} / \mathrm{ft}^{2}$ at $75 \mathrm{~Pa}$ for LifeSource, ${ }^{11} 0.24 \mathrm{cfm} / \mathrm{ft}^{2}$ at $75 \mathrm{~Pa}$ for Sierra, ${ }^{12}$ and $1.29 \mathrm{cfm} / \mathrm{ft}^{2}$ at $75 \mathrm{~Pa}$ for buildings without air barriers. ${ }^{13}$

Figures 19 and 20 illustrate the simulation results for the annual cooling energy consumption as a function of air leakage rate and suggest that the airtightness level of the LifeSource and the Sierra buildings can lead to an energy usage of about $370 \mathrm{MWh}$ and $46 \mathrm{MWh}$ per year, respectively. These Figures also suggest that the higher leakage rate from buildings without an air barrier could increase the cooling energy use of these buildings by 9 MWh in LifeSource and $38 \mathrm{MWh}$ in Sierra. In both buildings the effect of airtightness on cooling energy use is minor because of the relatively mild summers in the Minneapolis/St Paul area. Conversely, Figures 21 and 22 show that the annual heating energy increased by $35 \%$ (i.e., from 1,480 to $1,990 \mathrm{MBtu}$ ) in LifeSource and by $79 \%$ (i.e., from 4,600 to 8,230 MBtu) in Sierra, given that the winter season is much more severe than the summer. The effect of airtightness was higher in Sierra than in LifeSource partly because of their difference in window-to-wall ratio (WWR). Sierra just has a glass at its storefront (Figure 18); thus, its WWR is $\sim 6 \%$. In contrast, Figures 16 and 17 show quite a few windows that make LifeSource have a WWR of $\sim 25 \%$. A larger WWR means that windows have a greater contribution to the overall heat loses and gains through the building envelope, which in turn diminishes the effect of air leakage. Other contributing factors include that retail and office buildings have different occupancy schedules, plug and lighting loads, and types of HVAC systems.

\footnotetext{
11 The combined area of the walls and roof at the LifeSource building is $64,000 \mathrm{ft}^{2}$.

12 The combined area of the walls and roof at the Sierra building is $36,200 \mathrm{ft}^{2}$.

${ }^{13}$ Data in Table 2 from Emmerich and Persily (2014) were recalculated to exclude from the normalization the area of the slab on grade. Therefore, the air leakage rate of buildings without an air barrier increased from 0.86 to 1.29 $\mathrm{cfm} / \mathrm{ft}^{2}$ at $75 \mathrm{~Pa}$.
} 


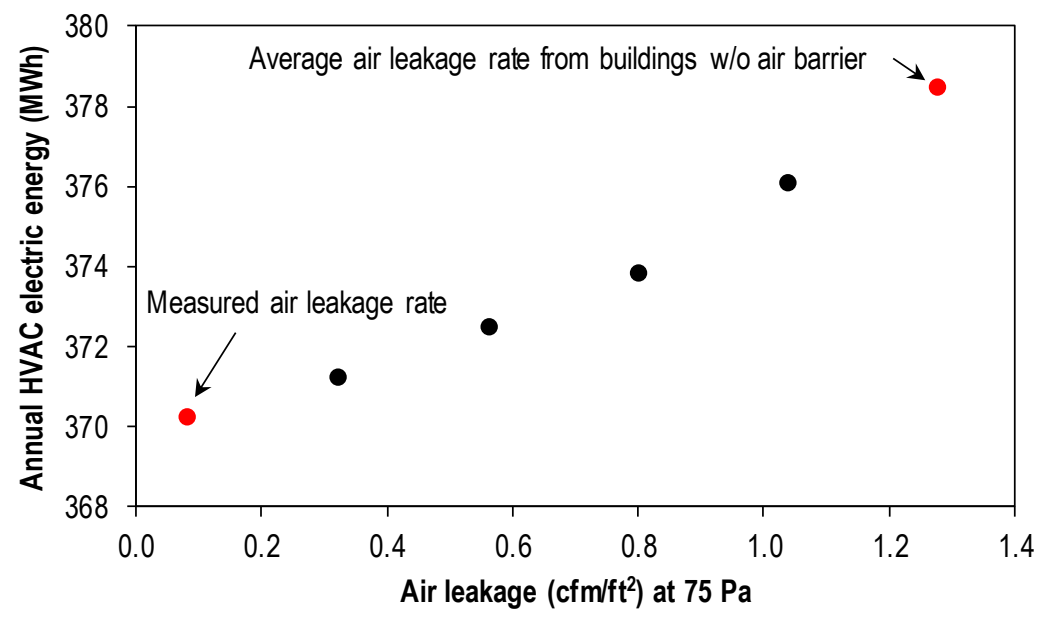

Figure 19. Simulation results of the annual HVAC electric energy consumed by the LifeSource building as a function of air leakage rate through the above grade walls and roof.

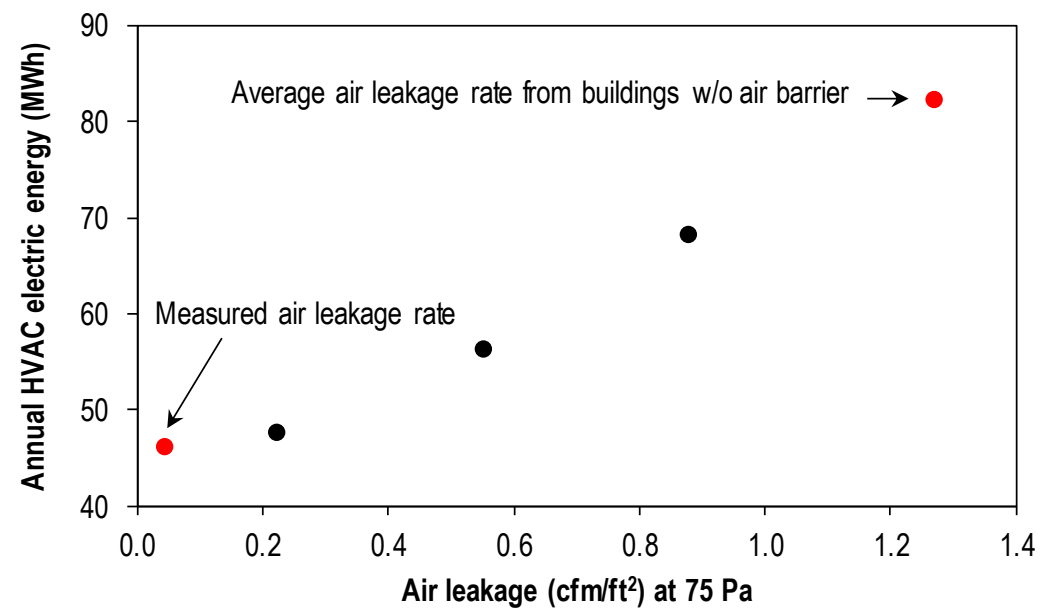

Figure 20. Simulation results of the annual HVAC electric energy consumed by the Sierra Trading Post building as a function of air leakage rate through the above grade walls and roof. 


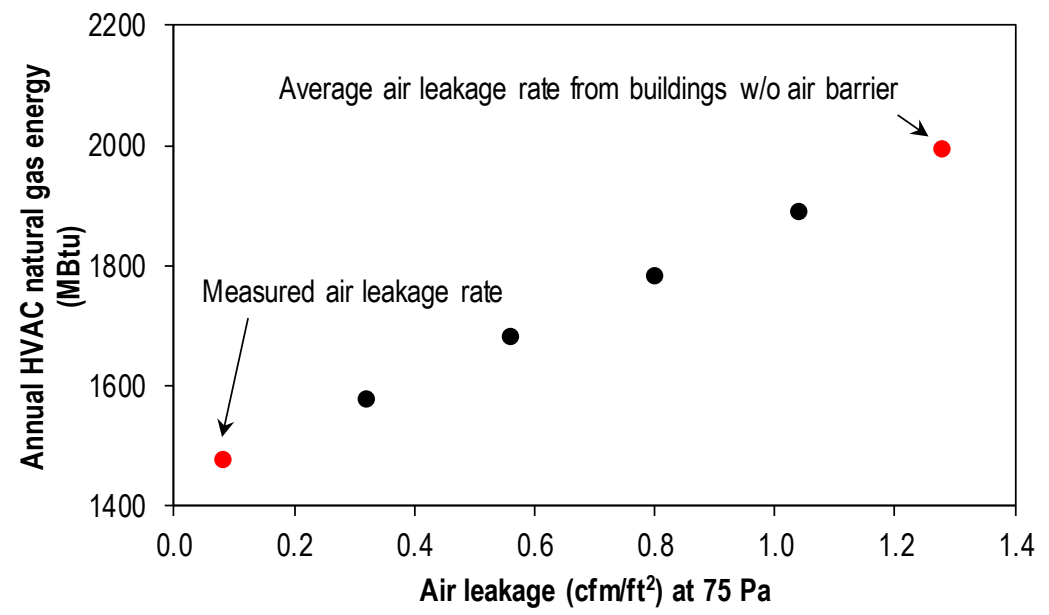

Figure 21. Simulation results of the annual HVAC natural gas energy consumed by the LifeSource building as a function of air leakage rate through the above grade walls and roof.

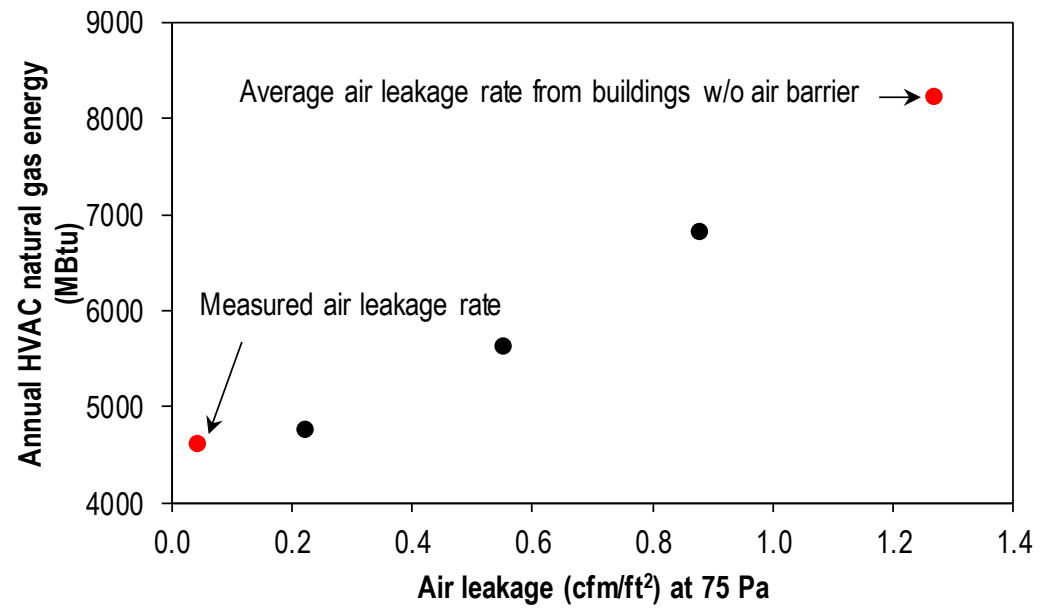

Figure 22. Simulation results of the annual HVAC natural gas energy consumed by the Sierra Trading Post building as a function of air leakage rate through the above grade walls and roof.

Figures 23 and 24 translate energy use to cost by assuming rates of $\$ 0.1$ per KWh for electricity and $\$ 7.3$ per MBtu for natural gas. Results indicate that by having an airtight envelope LifeSource saves about $\$ 4,600$ per year than if it lacked an air barrier system. Similarly, Sierra saves about $\$ 5,900$ per year. Note that the energy savings are higher in Sierra than in LifeSource because of differences between the two buildings that were described in the previous paragraph. 


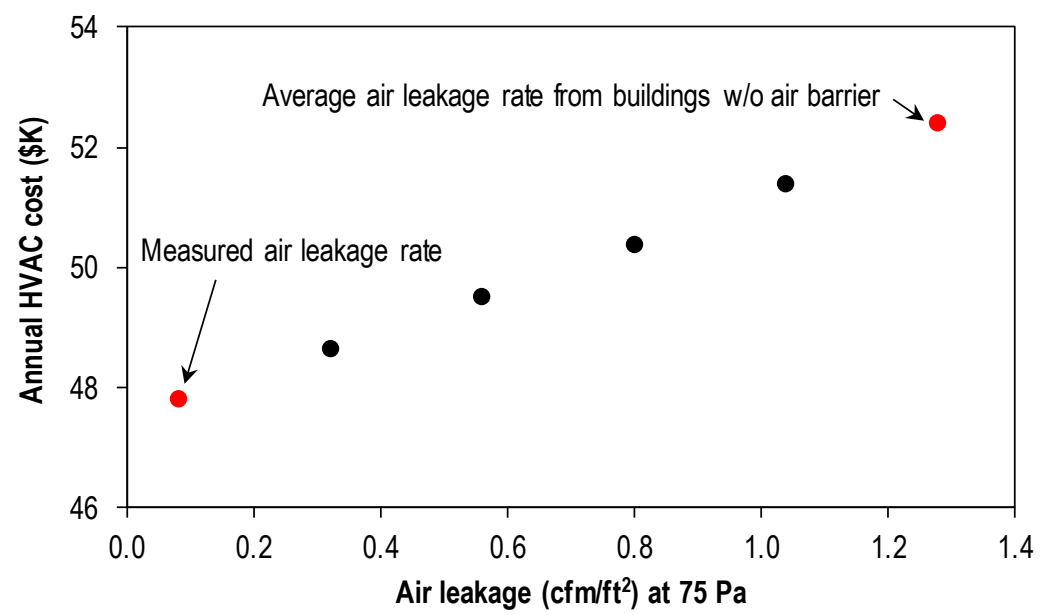

Figure 23. Simulation results of the annual HVAC energy cost for the LifeSource building as a function of air leakage rate through the above grade walls and roof.

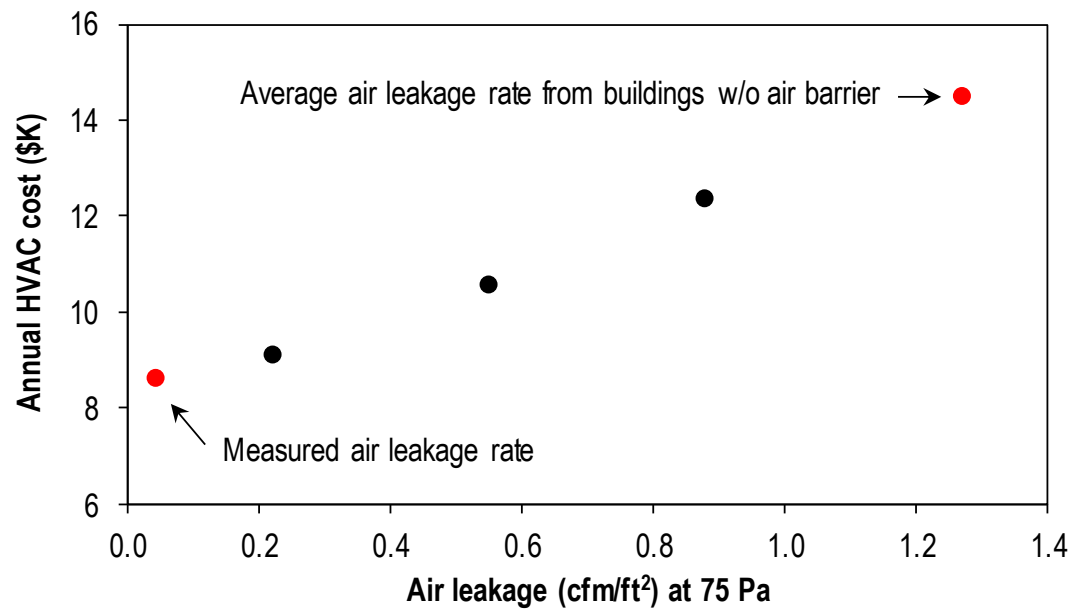

Figure 24. Simulation results of the annual HVAC energy cost for the Sierra Trading Post building as a function of air leakage rate through the above grade walls and roof.

Shrestha et al. (2016) are developing a free online calculator that estimates energy and cost savings due to improvements in airtightness for certain DOE commercial prototype buildings. ${ }^{14}$ The procedure that is followed by the calculator is more elaborate than the simulation steps that were followed with the LifeSource and the Sierra buildings in that the online tool uses weather data and building configurations to estimates hourly air leakage rates. The calculator may be useful to building owners and designers when trying to decide the airtightness level they want to target in new buildings and potential retrofits. Upcoming additions to the calculator include increasing the number of prototype buildings that it can analyze, and estimating decreases in moisture levels within building envelope assemblies due to lower air leakage rates.

\footnotetext{
${ }^{14} \mathrm{http}: / /$ www.airbarrier.org/technical-information/energy-savings-calculator/
} 


\section{CONCLUSIONS}

ORNL conducted field studies to evaluate the performance of three newly developed air- and waterresistive barriers: 3M 3015 primer-less self-adhered membrane, 3M 3015VP vapor permeable primerless self-adhered membrane, and 3M 2085VP vapor permeable fluid-applied air barrier membrane. The first assessment involved side-by-side evaluations in eight unoccupied test facilities in Cottage Grove, MN. After two years, findings indicate that the buildings with the new 3M membranes had slightly lower air leakage rates than the test facilities with traditional air barrier materials. The second study involved evaluations of the LifeSource building in Minneapolis, MN, and the Sierra Trading Post building in Woodbury, MN, which used the 3M 3015 and 3015VP membranes, respectively. Blower door test results show that LifeSource has an average air leakage rate of $0.06 \mathrm{cfm} / \mathrm{ft}^{2}$ at $75 \mathrm{~Pa}$ and the measurement in Sierra was $0.15 \mathrm{cfm} / \mathrm{ft}^{2}$ at $75 \mathrm{~Pa}$; these values are $85 \%$ and $63 \%$ lower than the IECC's $0.4 \mathrm{cfm} / \mathrm{ft}^{2}$ at 75 $\mathrm{Pa}$. Simulation results suggest that these low air leakage rates could translate to annual decreases in heating and cooling cost of \$4,600 in the LifeSource building and \$5,900 in the Sierra building when compared to similar structures that do not have an air barrier system. These field assessments are examples of the level of building envelope airtightness that can be achieved and their related energy and financial savings. 


\section{REFERENCES}

ASHRAE. 2002. Measurement of Energy and Demand Savings. ASHRAE Guideline 14-2014. Atlanta, GA: American Society of Heating, Refrigerating and Air-Conditioning Engineers, Inc.

DOE. 2014. Windows and Building Envelope Research and Development: Roadmap for Emerging Technologies. Washington, DC: US Department of Energy.

DOE. 2016a. EnergyPlus. Retrieved from https://energyplus.net.

DOE. 2016b. Commercial Prototype Building Models. Retrieved from https://www.energycodes.gov/commercial-prototype-building-models.

Emmerich SJ, Persily AK. 2014. Analysis of U.S Commercial Building Envelope Air Leakage Database to Support Sustainable Building Design. The International Journal of Ventilation, Vol 12, March 2014.

Hun DE. 2016. Materials that Improve the Cost-Effectiveness of Air Barrier Systems. Oak Ridge National Laboratory. ORNL/TM-2016/190.

IECC. 2015. International Energy Conservation Code. Illinois: International Code Council.

Shrestha SS, Ng L, Emmerich S, Hun D, Desjarlais A, Dalgleish L. 2016. Online Airtightness Savings Calculator for Commercial Buildings in the US, Canada and China. In: Proceedings from the Buildings Conference XIII, Clearwater, FL. 